\title{
An Analysis of HR Certification Value and Demand in Internet Job Announcements
}

\author{
Mitchell R. Gee, MSc, MBA \\ Dept. of Management, UNC Wilmington, Wilmington, NC 28403, USA \\ E-mail: gnbr94@gmail.com
}

\author{
Tammy G. Hunt, Ph.D. (corresponding author) \\ Professor of Management, Cameron School of Business \\ UNC Wilmington, Wilmington, NC 28403, USA \\ E-mail: huntt@uncw.edu \\ James B. Hunt, Ph.D. \\ Professor of Marketing, Cameron School of Business \\ UNC Wilmington, Wilmington, NC 28403, USA \\ E-mail: huntj@uncw.edu
}

Received:March 5, 2019 Accepted: April 2, 2019 Online published: April 16, 2019

doi:10.5296/ijhrs.v9i2.14459 URL: https://doi.org/10.5296/ijhrs.v9i2.14459

\begin{abstract}
As human resources certifications become prominent measures of occupational competency, HR professionals are increasingly curious about the value these credentials provide for individuals and organizations. This study examines connections between the demand for HR certifications and job posting sources, job type, industry, experience, and education requirements. Analyzing data from two job announcement websites, this study determines the worth of HR certifications by using demand for certifications as a signal of value. Expanding the work of Lyons et al. (2011), the present study serves as a temporal benchmark and finds nearly $20 \%$ of job announcements require or prefer a form of HR certification. Demand is positively related to experience, higher-level positions and education.
\end{abstract}

Keywords: HR certification, value, job announcements 


\section{Introduction}

Human resource (HR) professionals develop recruitment strategies that will attract talented candidates and they review and update job announcements to ensure the qualifications and duties are representative of the positions. This verification process benefits both potential employees and employers. Candidates can evaluate if they should put forth the effort to apply for a position by comparing their own qualifications to those requested in an announcement. As candidates who do not meet a position's qualifications may choose not to apply, this leaves employers with a talent pool of candidates who more likely meet the qualifications.

A significant challenge facing HR professionals is selecting skilled and knowledgeable candidates in a highly competitive labor market (Schramm, 2016). Candidates will likely have similar qualifications, compelling employers to identify key characteristics that distinguish top candidates from others. When making the determination of which applicants to interview and ultimately hire, recruiters must decide which key characteristics have the greatest potential to translate into successful performance.

To assist in the short-listing process, years of experience and educational background are two factors commonly used as requirements (Benson et al., 2004). As many candidates may have similar educational backgrounds and years of related experience, recruiters then must look to other factors such as technical skills or professional certifications. Many studies correlating work experience and educational background to job performance have been conducted, but not research relating HR certifications to job performance (Fertig et al., 2009).

Certifications can serve as an additional qualification for job applicants in tight labor markets, however the value of possessing these certifications has been questioned. HR certifications may be perceived as a differentiator among competitors, but if they have not been proven to result in better job performance, are they valuable? A lack of research establishing a potential link between certifications and performance has led practitioners and scholars to question the costs involved with earning HR certifications and the benefits that certifications can have for an individual's employability and career progression (Fertig et al., 2009; Lengnick-Hall and Aguinis, 2012).

As HR certifications are voluntary in nature, individuals likely want to know how valuable they are before dedicating time and resources to pursue certification. The impact of certification on job attainment, salary, job performance, and career advancement is a topic that researchers are only beginning to address (Putka et al., 2015). Cohen (2012) discusses the proliferation of HR certifications and the effects it has on supply and demand for HR certified professionals. Garza and Morgeson (2012) attempt to identify value from a subjective perspective. However, the literature lacks for studies measuring the objective / quantitative value of HR certification.

The present study adopts a framework used in previous studies to find less subjective measures of evaluating HR certifications. By assessing the demand for the Professional in Human Resources (PHR) and the Senior Professional in Human Resources (SPHR) certifications in internet job announcements, Aguinis et al. (2005) and Lyons et al. (2011) have gauged 
certification value via signaling theory (Spence, 1973; Celani and Singh, 2011). Aguinis et al. (2005) contends that demand for HR certification signals to an individual that employers value certification. The present study follows a similar job market signaling view to identify the value of a range of different HR certifications rather than looking solely at PHR and SPHR.

\section{Literature Review}

\subsection{Certifications Versus Licenses}

Beginning in the 1960s, the personnel department began to transform from a reactive function into an integral unit ensuring the organization was compliant with new health, safety, hiring, discrimination, retirement, and tax laws. Thus, a more direct link between the management of employees and the financial performance of the firm was established (Thite et al., 2015). This new perspective on people management expanded the responsibilities of the personnel department from simply hiring and firing on manager request to proactively managing recruitment, training, and development (Thite et al., 2015). A logical assumption is this created more impetus for HR to recruit and select the most talented and competent persons available.

The increased importance of competencies, employee performance, and development of human capital suggests a view that HR certifications which test competencies and develop employees are valuable to the organization. While Becker and Huselid (2006) and Pfeffer (1998) support the value of HR certifications, some may argue that certifications are less valuable than mandatory licenses as they are not required credentials. Licenses are mandatory certifications individuals need to legally perform specialized skills in their jobs (Murphy, et al., 2011). Controlled by governmental agencies, licenses are required in certain professions as a means of protecting the public from harmful practices.

Professional licenses and certifications require meeting a set of standards, passing an exam, typically paying a fee, and renewing the certification or license after a specified time period (Torpey, 2016). These requirements ensure individuals have a commitment to the intended field and possess at least a minimum body of knowledge or skills. Professionals possessing an HR certification are found to have a higher commitment to the field of HR than those without certification (Hsu and Yancey, 2015). Certifications represent extra commitment an individual puts forward when not required. In fact, voluntary certifications may represent more valuable signals to organizations than mandatory licenses. In both instances, a level of competency is demonstrated, but those who pursue voluntary certification demonstrate an affinity for developing themselves.

Certifications offer professionals in occupations that do not require a license a method for signaling to employers a proficiency in standards or body of knowledge of a specific job or industry. Third party accrediting organizations are typically responsible for administering and evaluating certification testing standards independent of the professional associations offering them (Credentialingexcellence.org, 2018). As professionals look for ways to be more competitive in the labor market, certifications offered by professional associations have become a way to distinguish oneself in his or her respective field. 


\subsection{HRM Certification Organizations}

The American Society for Personnel Administration (ASPA) was created in 1948 (Williamette.edu, 2018). ASPA set forth to provide certification by establishing the ASPA Accreditation Institute (AAI) in 1973. The AAI changed its name to the Personnel Accreditation Institute (PAI) in 1979, and in 1989 changed the name to what it is today: The Human Resources Certification Institute (HRCI) (Leonard, 2010). That same year, the ASPA renamed the organization to its present name, the Society for Human Resource Management (SHRM) (Leonard, 2010).

The HRCI is a third-party organization that administers the PHR and SPHR certification exams that respectively test tactical and strategic HR knowledge. SHRM was originally the professional association that offered testing preparation materials and educational seminars to prepare individuals for the exams (Cohen, 2012). However, the dynamic between the two organizations has changed.

In 2014, SHRM announced a major change in the type of certification it recommends. SHRM no longer provides preparation materials for the PHR and SPHR exams, and instead, works with a new accrediting organization to promote their own certifications. The new certifications, SHRM Certified Professional (SHRM-CP) and SHRM Senior Certified Professional (SHRM-SCP), are accredited by the Buros Center for Testing to set higher standards than the previously supported PHR and SPHR certifications (Shrm.org, 2018a). SHRM claims there are higher standards for passing the SHRM-CP and SCP exams, suggesting the value of these certifications is greater than the previous PHR and SPHR certifications.

The HRCI now offers professionals additional certification options to accommodate those who may benefit more from endorsements other than PHR and SPHR certifications. It appears HR professionals are seeing value in these certifications. As of January 2018, over 135,000 professionals have been certified via HRCI across eight certifications. Though this number is substantially smaller than that for SHRM certifications, it is the fastest growing human resource credential program (Ensslin, 2018).

The certifications offered by HRCI and SHRM cover portions of all HR functions, but other certifications test for specific HR function knowledge. For example, the IMPA-HR-CP, (International Public Management Association for Human Resources Certified Professional), tests a professional's mastery of HR competencies and knowledge solely in the public sector (IMPA-HR.org, 2017). Certifications from the International Foundation of Employee Benefit Plans test mastery of standards focusing on total employee compensation (Ifebp.org, 2018). If a portion of a certification's value is dependent upon an employer's ability to recognize and understand what the certification represents, there may be a decrease in value as more certifications are offered. Not only might an increase in the number of available HR certifications reduce their overall worth, but it may also make it difficult to distinguish value between different types of certifications. 


\subsection{Benefits and Value of HR Certification}

It is not uncommon for economists to think of the value of an object as depending not on the properties of the object itself, but rather reflecting the subjective tastes of the evaluator (Walsh and Lynch, 2003). The subjective theory of value in economics suggests the value of an object can fluctuate depending on an individual's perception of its utility (Menger, 1871), and the effort bargain theory of management describes the relationship between the amount of effort an individual is willing to put forth and the expectation of reward equivalent to the perceived effort exerted (Baldamus, 1961). It is important to remember that value is determined by the buyer, so the perception of an object's value changes according to buyer needs, the nature of the decision-making process, and effort required (Webster, 2005). Sidorchuk (2015) concludes that price, by itself, is not an adequate measure of value. Applying these ideas in the HR certification context, individuals considering certification likely add up the costs and effort needed to become certified, then compare them to the reward or value of being a certified HR professional.

The potential benefits commonly listed for HR certification range from currency, recognition, career advancement, pay increases, and mastery of a body of knowledge (Lengnick-Hall and Aguinis, 2012; Wiley, 1995). There is not yet consensus supporting these benefits among academics and practitioners. HR professionals will continue to operate under the subjective theory of value when evaluating these benefits until research confirms the relationship between certifications and job benefits. The present study adds to the ongoing investigation of the value of certifications in human resource positions by using market signaling theory and quantifying explicitly written preferences or requirements for these credentials in internet-based job announcements. The intention of this investigation is to make the benefits of certification more objective.

Signaling theory asserts that information provided by applicants serves as a signal to employers about the applicants' potential for successful job performance (Spence, 1973; Celani and Singh, 2011). As employers use certifications as one of a number of selection tools when creating job announcements, signaling theory provides a means for using HR certification demand in job announcements as a measure of a firm's perception of the value of HR certifications.

Aguinis et al. (2005) looked at the demand for PHR and SPHR certifications in job announcements, and respectively found only $.48 \%$ and $3.73 \%$ required or preferred certification. Their study compared the demand of PHR and SPHR certifications to factors including experience, job level, salary level, and job type, concluding that HR certifications were not an effective market signal of future job performance (Aguinis et al., 2005). However, Cohen (2012) contests this conclusion by referencing a replicate study (Lyons et al., 2011) that found demand for HR certifications to be an effective market signal to employers and individuals. He notes that overall preference for and requirement of credentials spiked to $15.6 \%$. The current study intends to test whether the increased job market signal value of HR certifications found by Lyons et al. (2011) is still present.

Noting the large increase from 2005 to 2011, our study seeks, in part, to conduct research 


\section{Macrothink}

International Journal of Human Resource Studies

ISSN 2162-3058 2019, Vol. 9, No. 2

similar to Aguinis et al. (2005) and Lyons et al. (2011). However, these studies only tested for HR and SPHR certifications, so this investigation takes advantage of an opportunity to compare value between HR certifications. The initial research (Aguinis et al., 2005) and the replication (Lyons et al., 2011) took place before 2014, when SHRM rebranded away from HRCI certifications. It is important to examine how signaling to employers may have changed (Thite et al., 2015).

The proliferation of new and existing HR certifications may affect how organizations perceive them as an effective market signal of future job performance. Lengnick-Hall and Aguinis (2012) created Table 1 displaying five professional associations and the 15 certifications they offered at that time.

Table 1. Popularity of HR certifications

\begin{tabular}{llr}
\hline Sponsoring organization & Certifications offered & \multicolumn{1}{c}{$\#$} \\
\cline { 2 - 3 } Society for Human Resource Management & PHR, SPHR, and GPHR & 111,788 \\
WorldatWork & CCP, CBP, GRP, WLCP, & 16,000 \\
International Foundation of Employee Benefit & CEBS, CMS, GBA, RPA & 18,663 \\
International Public Management Association & IPMA-HR-CP, & 5500 \\
for Human Resources & IPMA-CP Executive Level, & \\
American Society for Training and Development & IPMA-CS & \\
\hline
\end{tabular}

Source: Lengnick-Hall and Aguinis, 2012

Table 2 includes the professional associations listed by Lengnick-Hall and Aguinis (2012) with several recent additions. This shows the development of many new and specialized credentials. With so many certifications offered, the present study was designed to reassess the demand for HR certifications in general, but also to assess the differences for each certification. Comparisons allow professionals to understand which certifications to pursue if they are looking to gain a competitive edge. Given the increase in the number of certifications offered, organizations want to know the benefits of hiring credentialed candidates and the impact they will have on business outcomes. 
Table 2. Proliferation of HR certifications, 2018

\begin{tabular}{|c|c|}
\hline Professional Associations and Certifications \\
Organisation Name & Certifications Offered \\
\hline SHRM & SHRM-CP SHRM-SCP \\
HRCI & $\begin{array}{c}\text { PHR, PHRca, aPHR, aPHRi, } \\
\text { SPHRi, PHRca, } \\
\text { GPHR, }\end{array}$ \\
\hline WorldAtWork & $\begin{array}{r}\text { CCP, GRP, ACCP, CSCP, } \\
\text { CBP, WLCP }\end{array}$ \\
\hline Association for Talent \\
Development
\end{tabular}

Sources: SHRM.org, 2018b, HRCI.org, 2018, Worldatwork.org, 2018, Td.org, 2018, IFEBP.org, 2018, IPMA-HR.org, 2017, Human Capital Institute, 2018

SHRM writes in their certification handbook that professionals who earn these credentials will be able to benefit their organization through improved staff engagement, overall effectiveness, and operational proficiency (Shrm.org, 2018b). On HRCI's webpage, the association claims that by certifying entire HR departments, organizations can minimize exposure to corporate risk, create a stronger corporate culture, and demonstrate that HR staff has the skills to develop talent recruitment and retention strategies (Ensslin, 2018). If these benefits are perceived as true, HR professionals who are certified would signal to employers the possibility of earning some of the benefits by hiring certified applicants.

Lester et al. (2011) conducted a study surveying how supervisors view the impact of hiring certified professionals. Their study found $90 \%$ of respondents stated having credentialed HR professionals benefited their organization by gaining the HR department more credibility, reducing the risk of legal noncompliance, earning the increased confidence of others when making hiring decisions, and achieving higher confidence in the department's decisions (Lester et al., 2011). Furthermore, Fertig et al. (2009) state the amount and type of certifications a firm holds within its human capital can enhance its quality and innovation reputation with stakeholders.

On the other hand, Paxton (2012) warns that HR certification measures the knowledge of HR competencies and standards, but it does not measure an individual's ability to translate that knowledge into performance. Yet Paxton's view seems to be in the minority. Dye et al. (1993) found exams testing job knowledge, such as HR certification exams, have high validity in 
predicting job performance. In a study testing HR professionals' knowledge of best practices, Rynes et al. (2002) found SPHR credentialed professionals scored higher than non-credentialed colleagues. Additionally, a study performed by HRCI (Putka et al., 2015) found job performance of PHR and SPHR certified employees higher than non-certified employees in both tactical and strategic HR tasks. However, the authors note there are surprisingly few studies using empirical evidence to support the benefit of improved job performance due to certification (Putka et al., 2015). Considering the limited research supporting improved job performance, researchers should examine other individual benefits of certification.

As referenced by Lengnick-Hall and Aguinis (2012) and Wiley (1995), a potential benefit of becoming certified is an increased chance of initial employment and promotion. Rynes et al. (2002) support this relationship, finding individuals with SPHR certifications more likely to have higher-level jobs, longer tenure, more education, and a degree in HRM. A study by Lester et al (2010) measured the ability to obtain initial HR employment among individuals completing their undergraduate degrees. Students who had taken and successfully passed the PHR exam were more than twice as likely to obtain an HR job upon graduation compared to those who did not take or pass the exam (Lester et al. 2010).

Lester et al. (2011) found that HR certified professionals use certification to a greater extent when making hiring decisions than do non-certified professionals. If the findings of Lester et al (2011) and Lengnick-Hall and Aguinis (2012) exist in practice, earning an HR certification will increase an individual's chances of being hired as more certified HR professionals obtain hiring positions. This demonstrates arguably the most difficult challenge in researching HR certification value. An inherent bias of certified HR professionals favoring other certified HR professionals could accelerate the proliferation of HR certifications.

Lyons et al. (2011), the study that replicated Aguinis et al. (2005), showed the frequency of preferences and requirements for certified professionals by job level. Demand for certifications was highest among HR directors (26.2\%), generalists $(26.2 \%)$ and managers $(25 \%)$. Given that senior level positions are more likely to demand credentialed professionals than less senior roles, individuals seeking promotions to these positions will likely have higher chances if they possess a certification. The present research aims to identify any changes in senior-level demand for certifications since the Lyons et al (2011) research. In addition, this study seeks to identify which specific certifications senior level positions are demanding.

As stated by Fertig et al. (2009), professionals pursuing certification may be doing so to achieve higher salaries. The findings of studies researching the correlation between certification and salary are conflicting and inconclusive. However, The HRCI study reports higher pay for individuals with PHR and SPHR certifications (Putka et al., 2015). Hsu and Yancey (2015) also found positive correlations between salary and certification status.

\subsection{HR Certifications and Other Job Factors}

This study seeks to investigate the relationship between certification and the following factors: 
job announcement source, date listed, organization, location, job title, job type, industry, years of HR experience preferred, degree preferred, and certification status. These are particularly relevant to understanding the effectiveness of certification as a signal to both employers and employees. Aguinis et al. (2005) compared the geographic location (U.S. state) of announcements to the presence of a requirement or preference of certification and determined there was not a significant relationship between location and the demand for certification. There is also the question of whether having a certification serves as a stronger indicator of potential performance to employers in one U.S. state over another.

The industry in which an organization operates could also lead to differences in certification demand. Aguinis et al. (2005) found the demand for certification in accommodation / food services and manufacturing job announcements to be $10 \%$. The demand for HR certifications in health care and social assistance job announcements followed at 7.3\%. Lyons et al. (2011) found the industries with higher certification demand to be professional scientific and technical services $(32.3 \%)$, manufacturing $(17.5 \%)$, and health care and social assistance (13.2\%). Industries with higher demand for certifications could be associated with the number of regulatory standards. The present study aims to investigate the demand for HR certifications in each industry to identify any recent changes. Have the trends identified in previous studies continued? Are more industries recognizing the supposed value of certifications reflected by greater quantities of job announcements requiring or preferring certification?

Interactions between job title and certifications are also reviewed. The HRCI study (Putka et al., 2015) surveying HR supervisors found PHR and SPHR certified professionals were perceived to have a higher potential for senior level performance than those without certification. The Aguinis et al. (2005) and Lyons et al. (2011) studies support this claim with findings of higher demand for certifications in job announcements for more advanced positions such as director, generalist, and manager. The higher demand for certifications in senior-level positions may serve as an effective signal to individuals that certification is valuable if he or she is pursuing career progression. The higher demand for certifications in senior-level positions may also serve as an effective signal to employers that certification is valuable if organizations want to remain competitive when recruiting for these higher positions. Has this ongoing trend continued since 2011? Has the proliferation of certification demand caused any changes in which job titles require or prefer certification?

The present research aims to evaluate if certification is related to years of HR experience preferred. The average HR experience required for positions demanding certification in the Aguinis et al. (2005) study was 5.35 years. The average HR experience required for positions not demanding certification was 4.21 years (Aguinis et al., 2005). Lyons et al. (2011) found the average HR experience for positions demanding certification to be 6.76 years and positions that did not demand certification to be 4.87 years. These results support the idea that senior level positions require more years of HR experience and are more likely to require or prefer certifications. The demand for certification in positions requiring more years of experience supports the claim that certification is an effective signal of value. Has the trend of higher certification demand associated with more years of HR experience preferred continued? 
Has the proliferation of certifications caused an increase or decrease in the average years of experience required for positions requiring or preferring certification?

Another important indicator that organizations use as a tool for selecting the best talent is the requirement of educational degrees. Rynes et al. (2002) found SPHR certifications to be positively correlated with education level. Aguinis et al. (2005) studied the interaction between degree requirements and certification and determined there was not a statistical difference. In contrast, the Lyons et al. (2011) study did find a significant difference when comparing the level of education and the demand for certification. The study found vacancies requiring or preferring a graduate-level degree were also more likely to mention certifications than positions only requiring or preferring a bachelor's degree (Lyons et al., 2011). These inconsistencies warrant further research to determine if there is a relation between levels of education and certification. If the demand for certification is positively correlated with more years of experience and higher levels of education, individuals may conclude possessing a certification is beneficial when pursuing supervisory or senior level positions that also require advanced degrees.

\section{Research Methods}

\subsection{Research Design}

This study takes a job market signaling approach to offer a new, more objective method of evaluating HR certifications. In this context, the theory suggests the value of HR certifications can be determined by how often employers use certification as a selection tool to predict successful job performance. This allows the researcher to quantify the value of certifications in relation to their demand in the market.

Other methods of research were considered before the selection of using secondary data sources and market signaling theory. Lester et al. (2011) conducted primary research with the use of surveys distributed to HR supervisors to understand existing perceptions of certification value. While this method gives insight into the relationship between HR certifications and job performance, it relies heavily on individual, subjective perceptions that run the risk of bias. Hsu and Yancey (2015) offered another framework that focused on the perception HR professionals had regarding HR certifications compared to the perception supervisors had of these certifications. Their study delivers important results regarding how people value certification and the motivators involved with pursuing certification, but their findings suffer the same limitations as Lester et al. (2011).

The current study builds upon the quantitative secondary research approach utilized by Aguinis et al. (2005) and Lyons et al. (2011) to further identify the growing trend of organizations utilizing HR certifications as a selection criterion via job announcements uploaded to popular job posting sites in 2018.

\subsection{Data Collection}

The job posting sites Monster (27 million unique monthly users) and Indeed (200 million unique monthly users) were chosen for their public accessibility and high number of unique 


\section{Macrothink}

International Journal of Human Resource Studies

ISSN 2162-3058 2019, Vol. 9, No. 2

monthly users in online job posting. The following categories were identified as relevant to certification:

- Job posting source

- Job title

- Job type (full-time, part-time, temporary/contract)

- Industry

- Years of experience preferred

- Level of education preferred

- HR Certification (required, preferred, not listed)

Consistent with the Lyons et al. (2011) methodology, data were collected for five consecutive business days, 1:00pm-3:00pm EST daily, from Monster.com and Indeed.com for California, North Carolina, Pennsylvania, and Texas. The four states were selected to represent a diversity of U.S. regions by population and region. The data collection period took place between Monday, 06-25-18 and Friday, 06-29-18.

\subsection{Sample Selection}

A keyword search for "Human Resources" was used with the "Posted Today" and "Location" filters to accurately identify jobs that matched the criteria. Job announcements that did not contain any human resource job duties were excluded from the data sample. Duplicate postings were condensed to a single posting. A total of 965 job announcements were found to be unique, a number comparable to the Lyons et al. (2011) sample $(\mathrm{n}=1152)$. The following categories were further explored:

\subsubsection{Industry}

In the Aguinis et al. (2005) study, HR certification requirements or preferences from job announcements were categorized into specific industries to determine if there is a relationship between industry and job announcement request for a professional to be certified (Aguinis et al., 2005). This category was included to determine changes that occurred across industries from 2005 to 2018. Organizations were categorized using the North American Industry Classification System (NAICS) to maintain consistency.

Industry Classifications

- Health Care and Social Assistance

- Manufacturing and Construction

- Professional Services

- Banking and Financial Services

- Public Administration

- Technology

- Accommodation and Food Services

\subsubsection{Years of Experience}

"Years of experience required" and "years of experience preferred" were coded separately as there are typical ranges of years of experience listed rather than a fixed number of years 
required or preferred. To categorize years of experience, the study uses the lower extreme of any work experience ranges as the requirement and the upper extreme as the preferred years of experience. Job announcements that do not explicitly state a preference or requirement for years of experience, or requesting experience in a non-numerical manner, were not used for calculating average years of experience required or preferred. Any job announcements that did not explicitly list HR experience as a prerequisite were reviewed to ensure the job announcement was for an entry-level position containing HR specific job duties, but no experience required.

\subsubsection{Degree Requirement}

The "Degree Preferred" category is defined to list the highest level of education mentioned in the job announcement. This category does not distinguish between the level of education required and preferred, but rather lists the highest education level stated. This determination was made to simplify situations if the preferred level of education is listed as "Bachelor's or Master's" or "High School or Bachelor's."

\subsubsection{Certification Specifications}

HR certifications are divided into three separate categories titled, "HR Certifications Required," "HR Certifications Preferred," and "HR Certifications Not Required/Not Preferred/Not Listed." HR certifications from both the US and UK were used, including, but not limited to, PHR, SPHR, SHRM-CP, SHRM-SCP, PHR-Ca, and SPHR-Ca, CIPD certifications and other certifications from national certifying bodies such as HRCI, SHRM, and CIPD.

\subsubsection{Salary}

Cohen (2012) remarks that for data on certifications and pay to be valid and generalizable, a large longitudinal sample within a single compensation plan would be needed. She adds that gaining access to the information and being able to control for all other variables makes research on this topic extremely difficult (Cohen, 2012). Additionally, Aguinis et al. (2005) and Lester et al. (2010) did not find statistically significant evidence to support certifications leading to higher starting salaries or higher pay overall. Years of experience and job performance were found to be stronger predictors of salary (Lester et al., 2010). To give employers more freedom in determining wages, current job announcements on Monster.com and Indeed.com very rarely post salary ranges. For these reasons, data on salary was not collected.

\section{Analysis and Results}

\subsection{Data Collection Results}

After collecting the data from Monster.com and Indeed.com for five consecutive business days, 965 data points were found to be unique for HR positions; 560 results from Indeed.com while Monster.com returned 405 results. The job announcements spanned from entry-level positions to senior level positions varying in job type from full-time, part-time, contract and temporary work. Overall, 175 of the 965 (18.13\%) job announcements collected preferred a 
form of HR certification from applicants. Additionally, 16 of the 965 (1.66\%) job announcements collected required a form of HR certification.

\subsection{Job Title}

HR managers, generalists, and business partners account for the majority of the 175 positions that prefer a form of certification with relative values of $24.57 \%, 16 \%$, and $12.57 \%$ respectively. Following these are director (12\%), specialist $(9.14 \%)$ and recruiter $(5.14 \%)$. Lastly, the lowest percentage of positions preferring HR certifications were HR intern $(0 \%)$, trainer $(0.57 \%)$ and associate $(0.57 \%)$.

HR manager, generalist, director, business partner, and coordinator positions were the only positions that returned job announcements requiring applicants to hold a form of human resource certification. Six manager positions (37.5\%), four generalist positions (25\%), three director positions (18.75\%), two business partner positions (12.5\%) and one coordinator position $(6.25 \%)$ comprise the 16 announcements requiring certification.

\subsection{Job Type}

Data collected on job type resulted in the creation of four categories: Permanent full-time, permanent part-time, temporary/contract work and not listed. Permanent full-time positions made up the majority of job announcements with 849 results. Permanent part-time positions appeared in 12 announcements from the sample. Temporary or contract work, including internships, returned 102 job announcements. Lastly, two job announcements did not specify type of work.

Among job announcements preferring certification, $97.71 \%$ were permanent full-time, $0.57 \%$ permanent part-time, $1.71 \%$ temporary/contract work and $0 \%$ for the announcements without the job type explicitly listed. $100 \%$ of the job announcements requiring certification were for permanent full-time positions. Considering a large majority (87.98\%) of all job announcements were advertising permanent full-time positions, the results comparing HR certification demand and job type are not surprising.

\subsection{Industry}

Using the North American Industry Classification System (NAICS), industries were condensed into seven categories. Information regarding overall industry preferences and requirements were collected to determine which industries demand certification more.

In 175 job announcements preferring certification, Manufacturing and Construction (26.29\%), Professional Services (20\%), and Accommodation and Food Services (19.42\%) categories account for the top industries among announcements preferring HR certifications. Only 16 job announcements required an HR certification: Manufacturing and Construction (43.75\%), Professional Services (18.75\%) and Health Care and Social Assistance (12.5\%).

Investigating each industry independently also gives researchers and practitioners insight into the demand of HR certifications. Table 3 shows the relative percentages of certifications preferred and required by industry, including the total number of job announcements in each 
industry.

Table 3. Individual certification demand by industry

\begin{tabular}{|l|c|c|c|c|c|c|}
\hline \multicolumn{1}{|c|}{ Industries } & $\begin{array}{c}\text { Preferred } \\
\text { Certifications }\end{array}$ & $\begin{array}{c}\text { Total } \\
\text { Certifications }\end{array}$ & $\begin{array}{c}\text { Number } \\
\text { of } \\
\text { Industry } \\
\text { Entrees }\end{array}$ & $\begin{array}{c}\text { Preferred } \\
\text { Certifications } \\
\text { (\%) }\end{array}$ & $\begin{array}{c}\text { Required } \\
\text { Certifications } \\
\text { (\%) }\end{array}$ & $\begin{array}{c}\text { Certifications Not } \\
\text { Preferred/Required } \\
\text { (\%) }\end{array}$ \\
\hline $\begin{array}{l}\text { Banking and } \\
\text { Financial } \\
\text { Services }\end{array}$ & 11 & 1 & 44 & $25 \%$ & $2.27 \%$ & $72.73 \%$ \\
\hline $\begin{array}{l}\text { Healthcare and } \\
\text { Social } \\
\text { Assistance }\end{array}$ & 28 & 2 & 155 & $18.06 \%$ & $1.29 \%$ & $80.65 \%$ \\
\hline $\begin{array}{l}\text { Manufacturing } \\
\text { and } \\
\text { Construction }\end{array}$ & 46 & 7 & 182 & $24.44 \%$ & $3.89 \%$ & $71.67 \%$ \\
\hline $\begin{array}{l}\text { Professional } \\
\text { Services }\end{array}$ & 35 & 3 & 230 & $15.22 \%$ & $1.30 \%$ & $83.48 \%$ \\
\hline $\begin{array}{l}\text { Public } \\
\text { Administration }\end{array}$ & 6 & 1 & 23 & $26.09 \%$ & $4.35 \%$ & $69.57 \%$ \\
\hline Technology & 15 & 1 & 109 & $13.64 \%$ & $0.91 \%$ & $85.45 \%$ \\
\hline $\begin{array}{l}\text { Accomodation } \\
\text { and Food } \\
\text { services }\end{array}$ & 34 & 1 & 222 & $15.32 \%$ & $0.45 \%$ & $84.23 \%$ \\
\hline \begin{tabular}{l}
$\mid 75$ \\
\hline Totals
\end{tabular} & 16 & 965 & & & \\
\hline
\end{tabular}

\subsection{Experience}

The data were analyzed for years of experience preferred, with the most cited as five years $(22 \%)$, three years (15\%), and two years (12\%). Interestingly, $105(10.88 \%)$ of the announcements did not list a preferred number of years of experience but were advertising for a confirmed HR position.

Years of experienced preferred was identified across job announcements preferring and requiring certification. Of the 175 announcements preferring certification, 54 position vacancies preferred five years of HR experience. Three, seven and ten years of preferred HR experience occurred in 23,21 and 24 position vacancies respectively.

Years of HR experience preferred was also identified across job announcements requiring HR certification. Of the 16 announcements requiring certification, six job announcements preferred five years of HR experience. Three, seven, and ten years of preferred HR experience occurred in two, three and three job announcements respectively.

\subsection{Degree Preferred}

A majority of the vacancies (610) preferred a bachelor's degree as the highest level of education. The preference for certified individuals in job announcements spanned across all 


\section{Macrothink}

International Journal of Human Resource Studies

ISSN 2162-3058 2019, Vol. 9, No. 2

levels of education preferences except in job announcements preferring a $\mathrm{PhD}$ or in announcements that prefer education, but do not require it. Together, $95.84 \%$ of job announcements that prefer certification consisted of job announcements preferring a bachelor's or master's degree. These degree preferences in announcements account for $100 \%$ of all vacancies requiring HR certification.

\subsection{Certification Type}

In total, 175 of the 965 announcements preferred and 16 required some form of $\mathrm{HR}$ certification. In 111 of the 175 job announcements preferring HR certification, the organization listed more than one type of certification. Table 4 shows the frequency of the certifications mentioned. PHR and SPHR certifications were preferred the most, appearing in 135 and 99 of the 175 job announcements respectively. SHRM-CP, SHRM-SCP, and non-specific certifications followed as the most frequent certifications after PHR and SPHR.

As for the frequency of each certification type within the 16 job announcements that required certifications, 15 listed more than one type of HR certification. As in the job announcements preferring HR certification, PHR and SPHR certifications were required far more than all other forms of certification.

Table 4. The frequency of certification types preferred

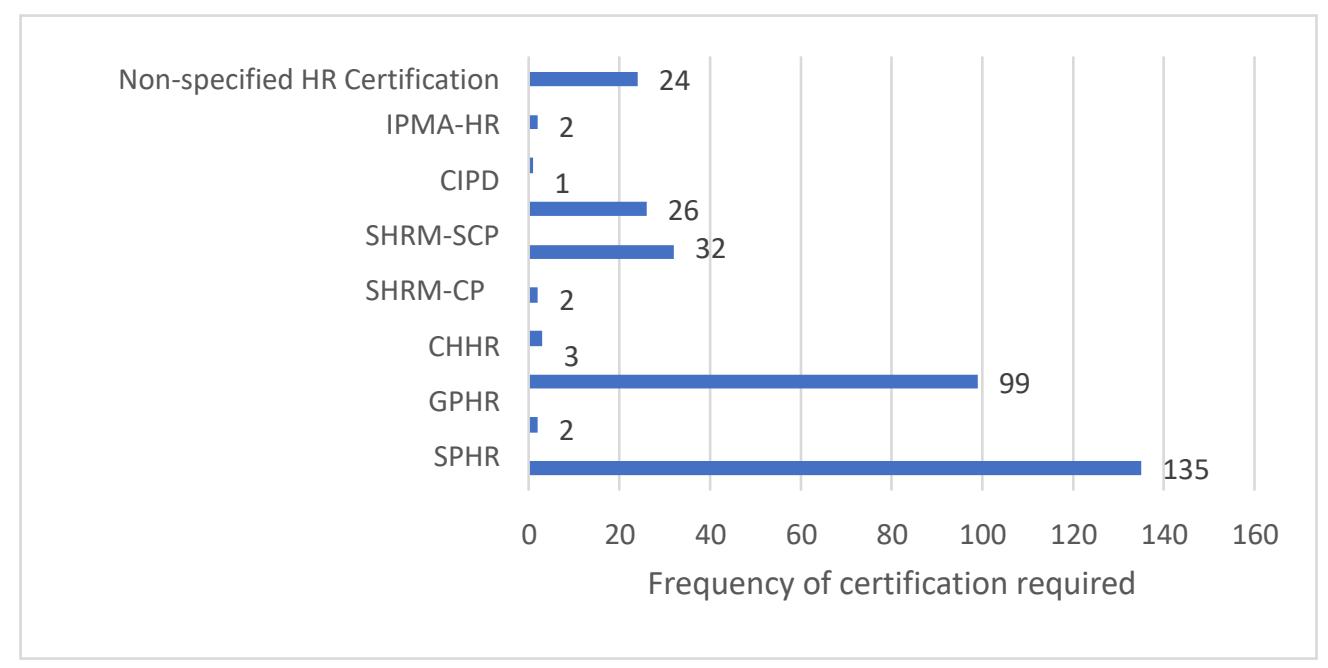

\section{Discussion}

The present study was conducted to examine the value of HR certifications for individuals and organizations by measuring the demand for these certifications in internet job announcements. Utilizing market signaling theory (Celani and Singh, 2011; Spence, 1973), the researchers investigated to determine if organizations valued certification enough to place a requirement or preference for them in job announcements. Our results suggest many organizations see certification as valuable and therefore include a statement expressing a demand for certification as a signal to candidates. Overall, $18.3 \%$ of job announcements preferred credentials. Job announcements requiring certification from applicants were present in $1.66 \%$ of the sample. Together, approximately $20 \%$ of all job announcements collected either preferred or required HR certifications from job candidates. Comparing this study's 
findings with past studies is useful in assessing the strength of the demand for HR certifications as a job market signal.

The Aguinis et al. (2005) study first identified the demand for certified HR professionals in online announcement sources, but determined the demand to be very low (4.22\%) and not an effective signal of value. Lyons et al. (2011) replicating the Aguinis et al. (2005) study and found a significant change in overall demand. This change suggests that more organizations are including statements of demand for certified individuals, thus signaling the organization's belief that individuals with certification will likely perform well and benefit the company. The Lyons et al (2011) study reported overall demand for HR certifications rose from $4.22 \%$ in 2005 to $15.6 \%$ of all job announcements. The authors credit the increase from $4.22 \%$ to $15.6 \%$ in certification demand to the proliferation of HR certifications over the six-year gap. Due to the significant change in results between the two previous studies, it was deemed important to identify any changes in this trend seven years after the last replication.

Our findings suggest the trend of organizations seeking out certified candidates has continued. The increased demand for these credentials further supports the notion that organizations are using HR certifications as a signal of value. As more organizations use certification as a way of effectively selecting talent, a perceived increase in the effort an individual has to exert to obtain employment is expected. Perceived effort is the time and energy required for a person to receive certification, while perceived benefit is the increased ability to compete for vacancies that require or prefer certifications. As employer demand for HR certifications continues to increase, the perceived value of possessing a certification is likely to increase for those who want to access as many job opportunities as possible. Not having a certification does not disqualify individuals from positions preferring certification (18.13\%), but it signals an individual's increased competitiveness to the organizations that prefer certification.

Next, comparisons between certification demand and industry were examined. Job announcements were classified using the North American Industry Classification System (NAICS). Job announcements preferring HR certification showed certain industries having higher certification demand than others. Like both Lyons et al. (2011) and Aguinis et al. (2005), the manufacturing and health care / social assistance industries were chief in preferring or requiring certification. The top three industries in the present study that preferred HR certifications in job announcements were manufacturing (26.29\%), professional services $(20 \%)$ and health care / social assistance (19.42\%). Job announcements requiring HR certification showed manufacturing, professional services, and health care/social assistance to make up $43.75 \%, 18.75 \%$ and $12.5 \%$ of the 16 announcements respectively.

With the proliferation of HR certifications since the Lyons et al (2011) study, an aim of the present study was to determine if the observed industries' demand for certifications has changed. Lyons et al (2011) found $17.50 \%$ of manufacturing jobs preferred certification while the present study found an increase to $24.44 \%$. Lyons et al (2011) found $13.2 \%$ of health care and social assistance jobs preferred certification, while this study found $18.06 \%$. The preference for certification indicated a decline in the professional services industry as Lyons et al (2011) study found $32.30 \%$ of job announcements preferred certification while the 
present study found only $15.22 \%$ of job announcements preferring certification. Fluctuations within industries over time may be explained by changes in perception of certifications or to changes in the number of regulatory standards present in certain industries.

The interactions between job titles, years of experience, level of education, certification type and demand for HR certifications offer more contributions to the value of HR certifications. Comparing the demand for certification to job titles gives insight into the value certifications have for employers and employees. The two previous studies showed statistically significant differences existed between job title and demand for certification. The results support this idea as job announcements for HR managers, generalists, and director positions were associated with higher rates of certification demand than other positions. We found managers, generalists, business partners, and directors to account for approximately $65 \%$ of the job announcements that preferred certification. These position titles also make up four of the five job announcements that required a form of HR certification. The data shows that the expansion of certifications available between 2011 and 2018 has not greatly affected position titles that require or prefer certifications.

Rynes et al. (2002) found SPHR certified professionals to hold higher-level jobs than non-certified professionals, and the present research supports this claim. The data show that higher-level job positions are more likely to require or prefer certifications than lower level job titles. The findings of Putka et al. (2015) identifying certification holders to have a higher potential for success in more senior level positions, support the present study's findings. As job announcements for higher-level positions are associated with greater demand for certifications, individuals can conclude that HR certifications are valuable signals of potential job success that organizations could use when recruiting for key positions.

Matching information on job titles with the findings on the relationship between HR certification demand and years of experience preferred will further support the claim that certification demand is an appropriate signal of value. The demand for certification in this data is related to years of experience similar to the findings in previous research. Lyons et al. (2011) found the required years of experience listed in job announcements having higher certification demand to be higher than years of experience required for job announcements that did not require or prefer certifications. The present study shows the average years of HR experience preferred in job announcements with a preference for certification to be 5.64 years. The average years of HR experience preferred in job announcements that did not state a preference for certified individuals are 4.42 years. Five years of HR experience was the number of years most frequently preferred from the job announcements preferring a HR certification. The results in the present study exhibit a decrease in number of years of HR experience preferred from the Lyons et al. (2011) study, but the relationship between years of experience and certification demand holds. Positions that require or prefer HR certifications also prefer more experience in comparison to positions that do not require or prefer HR certifications. Demand for HR certification can be a signal that organizations value certification in a similar way to how they value years of experience.

The relationship between education level and certification demand was examined. Within the 
610 job announcements preferring a bachelor's degree as the highest level of education, 132 announcements also preferred the candidate have an HR certification. Fourteen announcements in the same category required HR certification. Of the 133 job announcements preferring a master's degree, 35 also preferred HR certification. Only two of the 133 listings preferring a master's degree required the candidate to be certified. We found $21.64 \%$ of job announcements preferring a bachelor's degree also preferred certification while $25.93 \%$ of job announcements preferring master's degrees preferred certification. These statistics suggest that higher levels of education also result in higher levels of demand for certified professionals. These findings support Lyons et al. (2011) and provide further evidence that demand for certification is used as a signal of value to HR professionals. This signifies that gaining a certification will benefit an individual who plans to be more competitive for positions preferring these degrees.

Lastly, this study examined the various types of HR certifications available and looked for any differences in the demand for certification. As noted in the results section, although there are 175 job announcements that preferred certification, multiple certifications were included in 111 job announcements. In total, 10 different certifications were included 326 times within 175 announcements preferring at least one HR certification. PHR, SPHR, SHRM-CP, and SHRM-SCP were the certifications most often mentioned.

The creation of the SHRM-CP and SHRM-SCP certifications after SHRM's rebranding in 2014 (Shrm.org, 2018a) caused a fluctuation in which certifications were best known in the field of HR. The proliferation of types of HR certification leads one to wonder which certifications would be preferred or required. The demand for SPHR and PHR certifications is greater than the demand for other types of certifications in this study as they were included 135 and 99 times respectively. Demand for SHRM-CP and SHRM-SCP certifications is less than SPHR and PHR certifications having been mentioned 32 and 26 times respectively. The demand for all other HR certification types is low when compared to the four certifications listed above. The greater demand for HRCI and SHRM certifications as opposed to others indicates that acquiring these certifications is more valuable to professionals, because they are recognized as effective signals of potential job success.

\section{Limitations and Future Research}

A limitation of the present study is the relatively small sample size collected from job announcements. Generalizability may be limited as data were collected from the two most popular job announcement websites in only four states over five consecutive days. The present study's data collection sources, locations, and time frame represent only a small portion of the population of HR position vacancies across the United States, however, they are consistent with the methodology of the study we were replicating, Lyons et al. (2011). Future researchers are encouraged to collect data from multiple internet sources, professional associations, and internal job posting boards nationally or perhaps even globally where there may be significant differences in perception of the value of HR certifications.

The current study had to account for changes in the HR certification context since the last replication of Aguinis et al.'s (2005) study. Since Lyons et al.'s (2011) research examining 
only the demand for PHR and SPHR certifications, the creation of SHRM's and additional HR associations' certifications made researching demand for more than one type of certification necessary. The Aguinis et al. (2005) and Lyons et al. (2011) studies defined certification demand as the mentioning of a PHR or SPHR certification whether preferred or required. This study deviated from the earlier works by separating the demand for certification into "preferred any HR certifications" and "required any HR certifications". Future research linking HR certification and job performance should be conducted to consider potential creation of a licensure for HR professionals, as some organizations already require credentialed HR professionals. Further studies examining HR certification and post-certification job performance should be undertaken to establish causality and advance the field of study.

Another limitation of the study relates to job announcements that do not list a preference or requirement for HR certifications. Simply because a job announcement does not explicitly state a requirement or preference for certification does not mean it is not considered valuable to the organization. Aguinis et al. (2005) state that HR certification may be used as a tool later in the selection process. Lyons et al. (2011) address the fact that job posting websites have word limits that may affect the feasibility to explicitly state the preference or requirement for certification. The present study identified 774 of 965 (80.21\%) job announcements that did not require or prefer certification explicitly, therefore, this limitation likely has affected the findings.

\section{Conclusion}

Demand for certifications in job announcements serves as a signal to both individuals and organizations. This study lends insight into how the demand for HR certifications has changed since the proliferation of certifications and SHRM's transition from supporting PHR and SPHR certifications to SHRM-CP and SHRM-SCP certifications. Academic researchers remain curious about the value certifications have for HR professionals seeking initial employment or promotions within an organization. Gaining a clearer understanding of the value of these certifications can benefit professionals looking to advance in their careers and can also benefit employers seeking to improve recruitment and talent management processes.

There are two primary contributions this study offers HR researchers and practitioners regarding the value of HR certifications. First, the study utilizes a job market signal approach (Celani and Singh, 2011), i.e., signaling theory (Spence, 1973), to assess the value of HR certifications. Value was gauged for individuals and employers by quantifying the demand for HR certifications in internet-based job announcements. Previous studies by Aguinis et al. (2005) and Lyons et al. (2011) found an increase in the demand for HR certifications from $4.21 \%$ in 2005 to $15.6 \%$ in 2011 . The current study discovered $19.79 \%$ of the sampled job announcements required or preferred HR certifications in 2018. Demand for certifications is positively related to years of HR experience, level of education, and job title. These findings advance the notion that demand for HR certifications in job announcements signifies value for HR professionals and employers during the recruitment and selection process. 
Second, the study serves as a benchmark for the proliferation of HR certifications and demand. Beyond recognizing overall demand for HR certifications, the demand was identified for individual types of HR certifications. Since SHRM and other professional organizations are creating and updating certifications, it is important to document the changes in demand and perceptions of value in different contexts. The present study shows the demand for SHRM-CP and SHRM-SCP certifications to be about a third of that for PHR and SPHR certifications. Future HR research should continue to examine certification value for both individuals and organizations.

\section{References}

Aguinis, H., Michaelis, S. E., \& Jones, N. M. (2005). Demand for certified human resources professionals in internet-based job announcements. International Journal of Selection and Assessment, 160-171. https://doi.org/10.1111/j.0965-075X.2005.00310.x

Baldamus, W. (1961). Efficiency and effort: An analysis of industrial administration. Tavistock Publications.

Becker, B. E., \& Huselid, M. A. (2006). Strategic human resource management: Where do we go from here? Strategic Human Resource Management, 32(6), 898-925. https://doi.org/10.1177/0149206306293668

Benson, G. S., Finegold, D., \& Mohrman, S. A. (2004). You paid for the skills, now keep them: Tuition reimbursement and voluntary turnover. Academy of Management Journal, 47(3), 315-331.

Celani, A., \& Singh, P. (2011). Signaling theory and applicant attraction outcomes. Personnel Review, 40(2), 222-238. https://doi.org/10.1108/00483481111106093

Cohen, D. J. (2012). Identifying the value of HR certification: Clarification and more complex models required. Human Resource Management Review, 22(4), 258-265.

Credentialingexcellence.org. (n.d.). ICE NCCA Accreditation. [Online] Available at: http://www.credentialingexcellence.org/ncaa (July 4, 2018)

Dye, D. A., Reck, M., \& McDaniel, M. A. (1993). The validity of job knowledge measures. International Journal of Selection and Assessment, 1(3), 153-157. https://doi.org/10.1111/j.1468-2389.1993.tb00103.x

Ensslin, L. (2018). Certify your staff. [Online] Hrci.org. Available at: https://www.hrci.org/our- programs/certify-your-staff

Fertig, J., Zeitz, G., \& Blau, G. (2009). Building internal motivation for worker competency certifications: A critique and proposal. Human Resource Development Review, 8(2), 197-222. https://doi.org/10.1177/1534484309333614

Garza, A. S., \& Morgeson, F. P. (2012). Exploring the link between organizational values and human resource certification. Human Resource Management Review, 22, 271-278. https://doi.org/10.1016/j.hrmr.2012.06.011 
HRCI.org. (n.d.). Our certifications. [Online] Available at: https://www.hrci.org/ourprograms/our-certifications (June 8, 2018)

Hsu, Y., \& Yancey, G. (2015). The benefits of human resources certifications. Emporia State Research Studies, 50, 1-10.

Human Capital Institute. (n.d.). Events schedule - Human capital institute. [Online] Available at: http://www.hci.org/events/schedule?type=hci_class_instance (May 30, 2018)

IFEBP.org. (n.d.). IFEBP Certificate series. [Online] Available at: http://www.ifebp.org/Education/CertificatePrograms/CertificateSeries/Pages/default.aspx (July 10, 2018)

IPMA-HR.org. (n.d.). About IPMA-HR. [Online] Available at: https://www.ipma-hr.org/about (July 10, 2018)

Lengnick-Hall, M. L., \& Aguinis, H. (2012). What is the value of human resource certification? A multi-level framework for research. Human Resource Management Review, 22, 246-257. https://doi.org/10.1016/j.hrmr.2011.03.001

Leonard, B. (2010). History of the HR Certification Institute. [Online] HRCI.org. Available at: https://www.hrci.org/docs/default-source/web-files/history-of-hrci-updated-2009-pdf?sfvrsn= 0

Lester, S. W., Fertig, J., \& Dwyer, D. J. (2011). Do business leaders value human resource certification? Journal of Leadership and Organizational Studies, 18(3), 408-414. https://doi.org/10.1177/1548051811404422

Lester, S. W., Mencl, J., Maranto, C., Bourne, K., \& Keaveny, T. (2010). The impact of passing the professional in human resources exam on early career success for undergraduates entering the human resource field. International Journal of Selection and Assessment, 18(3), 282-290. https://doi.org/10.1111/j.1468-2389.2010.00511.x

Lyons, B. D., Mueller, L. M., Gruys, M. L., \& Meyers, A. J. (2011). A re-examination of the web-based job demand for PHR and SPHR certifications in the United States. Human Resource Management, 51(5), 769-788. https://doi.org/10.1002/hrm.21496

Menger, C. (1871). Principles of economics. English translation 1976. Auburn, AL: Ludwig von Mises Institute.

Murphy, R. O., Ackermann, K. A., \& Handgraaf, M. J. J. (2011). Measuring social value orientation, Judgement and Decision Making, 6(8), 771-781. https://doi.org/10.2139/ssrn.1804189

Paxton, R. A. (2012). A practitioner's perspective on the value of PHR and SPHR certification. Human Resource Management Review, 22(4), 279-281. https://doi.org/10.1016/j.hrmr.2012.03.002

Pfeffer, J. (1998). The human equation: Building profits by putting people first. New York: McGraw-Hill Company. 
Putka, D. J., Paullin, C., Beatty, A. S., Medsker, G. J., Caramagno, J. P., \& Ginter, R. (2015). An evaluation of the value of HR certification for individuals and organizations. Human Research Organization, 78, 1-45.

Rynes, S. L., Colbert, A. E., \& Brown, K. G. (2002). HR professionals' beliefs about effective human resource practices: Correspondence between research and practice. Human Resource Management, 41(2), 149-174. https://doi.org/10.1002/hrm.10029

Schramm, J. (2016). The big issues facing HR. [Online] SHRM.org Available at: https://www.shrm.org/hr-today/news/hr-magazine/0316/pages/the-big-issues-facing-hr.aspx

SHRM.org. (n.d.a.). 2018 SHRM accreditation. [Online] Available at: https://www.shrm.org/certification/about/Pages/shrm-accreditation.aspx (July 14, 2018)

SHRM.org. (n.d.b.). 2018 SHRM certification handbook. [Online] Available at: https://www.shrm.org/certification/Documents/Certification-HandbookFINAL.pdf (June 20, 2018)

Sidorchuk, R. (2015). The concept of value in the theory of marketing. Asian Social Science, 11(9), 320-325. https://doi.org/10.5539/ass.v11n9p320

Spence, M. (1973). Job market signaling. The Quarterly Journal of Economics, 87(3), 355-374. https://doi.org/10.2307/1882010

TD.org. (n.d.). ATD certification. [Online] Available at: https://www.td.org/certification (May $18,2018)$

Thite, M., Kavanagh, M., \& Johnson, R. (2015). The evolution of human resource management and human resource information systems. In human resource information systems, Sage Publications, 2-34.

Torpey, E. (2016). Will I need a license or certification for my job? Career outlook: U.S. Bureau of Labor Statistics. [Online] Bls.gov. Available at: https://www.bls.gov/careeroutlook/2016/article/will-i-need-a-license-orcertification.htm

Walsh, A., \& Lynch, T. (2003). The development of price formation theory and subjectivism about ultimate values. Journal of Applied Philosophy, 20(3), 263-278. https://doi.org/10.1046/j.0264-3758.2003.00252.x

Webster, F. E. Jr. (2005). Industrial marketing strategy. Moscow: Publishing House of Grebennikov.

Wiley, C. (1995). Reexamining professional certification in human resource management. Human Resource Management, 34(2), 269-289. https://doi.org/10.1002/hrm.3930340204

Willamette.edu. (n.d.). About SHRM. [Online] Available at: http://willamette.edu/org/shrm/about/index.html (July 5, 2018)

Worldatwork.org. (n.d.). Certifications. [Online] Available at: https://www.worldatwork.org/certification/ (April 11, 2018) 


\section{Copyright Disclaimer}

Copyright for this article is retained by the author(s), with first publication rights granted to the journal.

This is an open-access article distributed under the terms and conditions of the Creative Commons Attribution license (http://creativecommons.org/licenses/by/4.0/). 